\title{
Between Selves and Collectivities: Toward a Jurisprudence of Identity
}

\author{
Meir Dan-Cohen $\uparrow$
}

\section{PRoblems of Legal ONTOLOGY}

For quite a while now, sociologists, political scientists, and lawyers have emphasized the importance of what they have alternately referred to as mediating or intermediate social structures. ${ }^{1}$ Although the two labels are not synonymous-one implies a function while the other connotes relative location-they conjure up the same image. It consists in a polarity, or more accurately a confrontation, between individuals on the one side and

$\dagger$ Professor of Law, Boalt Hall School of Law, University of California, Berkeley. Copyright 1994 by Meir Dan-Cohen. I would like to thank my friends and colleagues Bruce Ackerman, Sanford Kadish, Sheldon Messinger, Robert Post, Edward Rubin, Marjorie Shultz, Stephen Sugarman, Jan Vetter, Jeremy Waldron, and Frank Zimring, and the Editors of this Review for their helpful comments.

1 For the former usage, see Peter L. Berger and Richard John Neuhaus, To Empower People: The Role of Mediating Structures in Public Policy (American Enterprise Institute, 1977); Bruce Hafen, Developing Student Expression through Institutional Authority: Public Schools as Mediating Structures, 48 Ohio St L J 663 (1987). The latter appears in, for example, Stanley Ingber, Rediscovering the Communal Worth of Individual Rights: The First Amendment in Institutional Contexts, 69 Tex L Rev 1 (1990). The terms are sometimes combined: Anne Dailey depicts "the family as an intermediate political institution, one that mediates the direct relationship between the individual and the state." Anne $\mathbf{C}$. Dailey, Constitutional Privacy and the Just Family, 67 Tulane L Rev 955, 961 (1993). 
the state on the other, with mediating social structures interposed between the two polar entities.

The mediation, as commonly understood, has a negative and a positive side. Negative mediation consists in protecting individuals from the state. Protection is needed because of the state's oppressive propensity on the one hand and individuals' vulnerability on the other. Mediating institutions provide individuals with at least partial shelters from the state's power and with a fulcrum for resistance. Positive mediation remedies a different problem. People derive indispensable spiritual and moral sustenance from collective life, but the state is ill-equipped to provide it. It is too large, remote, bureaucratic, and homogenous to be able to satisfy diverse individual needs. While serving as protective buffers, mediating institutions also create habitats within which individuals can flourish. ${ }^{2}$

However, this seemingly happy solution to the confrontation between individuals and the state runs into some well-known difficulties. Through mechanisms such as "the iron rule of oligarchy,"3 mediating institutions can themselves develop oppressive tendencies, leaving individuals trapped and suffocated. The only source of reprieve now seems to be the state that can secure individuals' rights within and against the various institutions. The dialectic of the state's intervention in the affairs of mediating institutions is, however, a vicious one. Don't the individuals who call upon the state's assistance knowingly bring in a Trojan Horse of gigantic proportions?

Much of the literature on mediating institutions addresses this dilemma and this dialectic. In doing so it has greatly illuminated a genuine problem and a major aspect of our collective life. However, the perspective provided by the standard picture remains a limited one, and by focusing our attention on one set of problems it diverts us from others. This is not by itself an objection. Every social theory must be based on great simplification and idealization. Still, given how accustomed we have become to the standard picture, it may be time to take a fresh look at the same terrain from a different angle. The motivation for replacing the traditional picture goes beyond a sense of its theoretical

2 Professor Cass Sunstein provides a succinct version of the two aspects of mediation: "Intermediate organizations ... serve both as checks on government and as arenas for the cultivation and expression of republican virtues." Cass R. Sunstein, Beyond the Republican Revival, 97 Yale L J 1539, 1572 (1988).

3 See Robert Michels, Political Parties (Free Press, 1962) (Eden Paul and Cedar Paul, trans). 
staleness. There are specific reasons to doubt the adequacy of the present simplifications. I will use such doubts as tools with which to dismantle ("deconstruct" would have too heavy connotations) the prevailing picture. This destructive effort will then allow me to introduce an alternative conceptual scheme in the following Section.

A central feature of the traditional approach to intermediate institutions is a three-way division of the social world in which the state is separated out as a distinct kind of entity. However, both the uniqueness and the unity that this approach ascribes to the state are questionable.

Consider unity first. For many purposes, it is more fruitful and accurate to view the state (or government) as a loose coalition of more or less independent collectivities. This conception of the state results primarily from the enormous expansion of government and the scope of its operations. The large size and complexity of modern government bring about a relatively high degree of decentralization. The decentralized units, in turn, undergo a process of bureaucratization in which they define their own subgoals, develop their peculiar operating procedures, carve out areas of special expertise, and become attached to their own constituencies. They thus grow farther apart, attaining an increasing level of functional independence that makes subsuming them under a single unifying category such as "government" less plausible or informative. ${ }^{4}$

Partly as a consequence, the dividing line between "government" and "private" organizations is progressively blurred. ${ }^{5}$ Quasi-governmental units now exist in which governmental and private resources are mixed; these new organizations teeter on the (vanishing) borderline between the public and the private spheres. ${ }^{6}$ By the process of "contracting out," "private" enter-

- On decentralization and loss of central control in government, see, for example, Michael D. Reagan, The Managed Economy 222-33 (Oxford, 1963). Professor Dahl points out that "[t]he national government is one out of more than ninety thousand governments of all kinds existing within the boundaries of the United States." Robert A. Dahl, Pluralist Democracy in the United States: Conflict and Consent 171 (Rand McNally, 1967). Compare Graham T. Allison, Essence of Decision: Explaining the Cuban Missile Crisis 67 (Little, Brown, 1971): "[A] government consists of a conglomerate of semi-feudal, loosely allied organizations, each with a substantial life of its own."

- See Grant McConnell, Private Power and American Democracy (Knopf, 1966); John Kenneth Galbraith, The New Industrial State 234 (Houghton Mifflin, 4th ed 1971). For a discussion of this phenomenon in a legal theoretical context, see Roberto Mangabeira Unger, Knowledge \& Politics 175-90 (Free Press, 1975).

- See, for example, the communication satellite system, discussed in this context in Reagan, The Managed Economy at 190 (cited in note 4). 
prises undertake traditionally governmental functions, but within the framework of an ongoing contractual and supervisory relationship with governmental agencies. In other "private" sectors, the government regulates to such an extent that nongovernment actors have no greater independence than that afforded some agencies more formally a part of the governmental structure. ${ }^{7}$

The twin tendencies of government toward decentralization and bureaucratization thus suggest an essential similarity and continuity with nongovernmental collective entities. By disaggregating the state we accordingly question not just its unity but its uniqueness as well. The traditional juxtaposition of individual and state depends on viewing the latter as possessing a unique combination of properties that make it distinctively inimical to the individual. Specifically, the state is thought to be distinguished by its size, its bureaucratic complexity, and its monopoly over coercive power. Clearly the disaggregation of the state undermines the first two characteristics-many other collective entities, such as large corporations, resemble both in size and in bureaucratic complexity the separate units of which the state is composed.

But the issue of coercion is not much different. Here too we must recognize the multiplicity of legitimate arms-bearing, institutionalized centers of coercive power-witness university police-as well as the relative de facto powerlessness of many government units. To insist that such "privately" exercised coercion occurs only at the state's sufferance misses the boat twice. First, it is doubtful whether the state could, if it wanted, eliminate all such use of force; and second, such insistence on the state's supremacy reinstates the unitary conception of the state from which the argument has already departed. We should recognize instead that different institutions perform different roles with regard to both using force and legitimating it; it is misleading always to combine them in a single, supposedly unitary, and hence unique collectivity called the state.

None of this means to suggest that we completely banish the state from our legal ontology. The conclusion rather is that we should invoke the state-as the label of a single, unified collectivity-more sparingly and critically, and even then view it as a less distinct member in a large and heterogeneous array of collective entities that populate society. ${ }^{8}$

7 Public utilities are the obvious example.

8 That the standard picture is wrong in associating the combination of size, bureau- 
The result of these considerations is a picture of society as consisting of individuals and collective entities, but this picture raises problems of its own. What exactly is the relationship between, or more grandiosely, the ontological status of the two types of entity? The natural tendency is to give priority to one entity or the other. Privileging individuals follows the tattered banner of methodological individualism. Treating collectivities as simply the aggregates of individuals has been subjected to sustained and well-known criticisms, which I need not rehearse here. ${ }^{9}$ However, this approach can be criticized not just for its deficient account of collectivities, but also for an inadequate, overly simplistic conception of individuals. Taking individuals as basic building blocks for purposes of social analysis ignores their essentially troubled identities and the role played by society in the construction of selves. ${ }^{10}$

The opposite approach-implicit, for example, in communitarian writings-gives ontological primacy to collective entities, viewing individuals as their products or artifacts. ${ }^{11}$ We must, however, sharply distinguish here the plausible view that society or culture determines individual identities, and the much less compelling contention that such identities find their source or foundation in the specific collective configurations with which individuals are affiliated. Moreover, even if we would concede that some collective entities form their members' identities, such a claim would still remain senseless with regard to other collectivities.

An apparently easy way to avoid both an individualistic and a collectivist reductionism would be to adopt a dualistic approach that treats individuals and collectivities as equally primary and

cracy, and coercion exclusively with the state does not mean that it is also mistaken in highlighting the special significance of these factors. In revising the standard picture we should not lose sight of this point.

9 See, for example, Maurice Mandelbaum, Societal Facts, and Ernst Gellner, Holism Versus Individualism in History and Sociology, both in Patrick Gardiner, ed, Theories of History: Readings from Classical and Contemporary Sources 476-88; 488-503 (Free Press, 1959); K.J. Scott, Methodological and Epistemological Individualism, in John O'Neill, ed, Modes of Individualism and Collectivism 215-20 (Heinemann Educational, 1973); Steven Lukes, Methodological Individualism Reconsidered, in Alan Ryan, ed, The Philosophy of Social Explanation 119-29 (1973).

${ }_{10}$ The primary modern text on the social origins of the self is George H. Mead, Mind, Self, and Society from the Standpoint of a Social Behaviorist (Chicago, 1974) (Charles W. Morris, ed). See also Peter L. Berger and Thomas Luckmann, The Social Construction of Reality: A Treatise in the Sociology of Knowledge 159-65 (Doubleday, 1966).

"This is, for example, a central theme in Michael Sandel's influential critique of Rawls. See Michael Sandel, Liberalism and the Limits of Justice (Cambridge, 1982). 
irreducible entities. Such dualism, however, would foreclose the possibility, urged by communitarians, of a deep connection and interpenetration between selves and collectivities. Can we keep this possibility alive without lapsing into a collectivist reductionism?

\section{ROLE-ATOMISM}

My description of the simplifications and shortcomings of the standard picture has been tendentious. It was designed to pave the way for an alternative picture I want to introduce. It did so by encouraging certain expectations that such a picture ought to fulfill. Let me briefly enumerate these expectations. First, the alternative picture should dislodge the vision of the state as a unique, unified entity by disaggregating it into the myriad collectivities of which it consists. The emphasis should be instead on the triple features of size, bureaucracy, and coercion, no matter how the collectivities possessing them have been traditionally classified. Correspondingly, the picture should capture the problem of individual identity and society's role in shaping the self. Furthermore, while avoiding the reductionism of either methodological individualism or collectivism, our new picture should also steer away from the sharp dichotomy between self and collectivity, and express the deep affinities between the two.

I start from the idea of a social role, such as that of a parent or a telephone operator. We are all sufficiently familiar with such roles that a formal definition will be unnecessarily confining. Roughly, a role involves a patterned set of expectations regarding modes of behavior as well as the mental states, such as intentions, desires, and beliefs, that are thought to properly underlie or accompany the expected behavior. ${ }^{12}$ I will treat roles as basic building blocks, or better yet, as atoms in a metaphoric social space. We encounter such roles in the form of intelligible modes of behavior, where intelligibility results from conformity to a recognizable pattern described in the role's "script."13 We can accordingly distinguish in a role two aspects: a formal aspect, consisting in the social norms that form the role's script; and a ma-

12 There is a vast sociological literature on the concept of role. For some sources and references to the standard use of the term, see Bruce J. Biddle and Edwin J. Thomas, eds, Role Theory: Concepts and Research (Wiley, 1966). The approach I present is probably closest to that of Talcot Parsons, The Social System (Free Press, 1951).

${ }^{13}$ On the notion of social scripts, see, for example, John H. Gagnon and William Simon, Sexual Conduct: The Social Sources of Human Sexuality 19-26 (Aldine, 1973). 
terial aspect, consisting in the actual patterned behavior and the requisite states of mind that conform to the script.

Relatedly, there are two ways in which different roles can appear connected so as to form relatively stable and recognizable clusters: roles can have a formal connection with each other or a material one. A formal connection among a cluster of roles is created by the scripts of the member roles. I will call such a formal connection coordination. By contrast, a material connection among roles-call it proximity - exists when the actual roleperformances and their underlying mental states are systematically connected. We can now recognize two ways in which roles can be synthesized or unified into composite entities. A formal, coordinated cluster of roles forms a collective entity (or a collectivity for short); a material cluster of proximate roles is a self (or an individual).

Consider an example. I am both a father and a law professor. What makes both of these roles mine? It should be first observed that, insofar as my existence in social space is concerned, the answer cannot be given in terms of some underlying, ontologically prior "substance" that can be said to possess and to unify both of these roles. The "mine" in question is accordingly not one of possession but one of identity: ${ }^{14}$ the two roles are among the constitutive elements of my social identity. In the absence of some third substance, we must seek the connection between the roles in the roles themselves. ${ }^{15}$ Such a connection will be found in a high level of intersection, overlap, and dovetailing in forms of behavior and mental states that characterize the enactment of these roles. Of course, these roles do not by themselves exhaust my identity. To form a self they must similarly interrelate with numerous other roles, forming together a relatively dense, cohesive, stable core that becomes the putative subject to whom possession of the various roles with their attendant actions and states of mind is conventionally ascribed.

Focus now on my role as father. The script of this role-the description of the patterned expectations I ought to fulfill behaviorally, mentally, and emotionally-will make essential and systematic reference to my children and my wife, just as the

14 I borrow this formulation from Sandel. See his Liberalism and the Limits of Justice at 56 (cited in note 11).

${ }^{15}$ The absence of such a substance is Derek Parfit's main thesis about the self. See his Reasons and Persons (Clarendon, 1984). However, by limiting my treatment to the "social self" I try to elide the more fundamental metaphysical questions that Parfit raises. 
scripts of the latter roles will reciprocally refer to mine. These coordinated formal connections form the D-C family. Similarly, the script of my role as law professor includes numerous references to, say, my dean and my colleagues. I am expected, for example, to show up when summoned by the former and to comment on the latter's manuscripts. Again, the roles of the dean and of my colleagues contain corresponding references to my role, thus forming together the coordinated formal cluster known as Boalt Hall.

It is easy to see how the approach I have just outlined-I call it role-atomism-meets some of the expectations raised by our discussion of the standard picture. By using roles as the basic building blocks from which we construct both individuals and collectivities we avoid reducing one type of entity to the other, while expressing both their common social origin and their deep, constitutive relationships. These are considerable theoretical gains, but they may not have yet been honestly earned. We must add more substance to the suggested approach before we can make any claims for it. In the next Section I discuss in greater detail the idea of constructing selves out of social roles, and then in the following Section I consider more fully the construction of collectivities out of the same materials. At that point, we will be in a better position to spell out and assess some of the normative, specifically legal ramifications of our revised social ontology.

\section{The Material Synthesis: Constructing Selves}

My aim in this Section is to add detail and credibility to the construction of selves out of social roles situated at varying distances from each other. In doing so, I do not mean to engage in a full-fledged discussion of the metaphysics of selfhood-clearly one of the most involved and persistent issues in the history of philosophy. By using the "proximity" idiom to describe the relationship among roles that form a single self, I mean to tap one particular, distinctly social conception of the self. This conception is most directly related to Erving Goffman's work. Goffman uses a dramaturgical imagery to convey the idea that the self consists, at least in part, in the social roles it enacts. ${ }^{16}$ Central to this picture is the concept of role distance, which conveys the self's capacity to locate itself, metaphorically speaking, at variable

16 The most comprehensive statement of his approach can be found in Frame Analysis (Harper \& Row, 1974). 
distances from the different roles that it occupies. ${ }^{17}$ Given its dramaturgical origins, the best way to introduce the suggested conception of the self is a theatrical example. ${ }^{18} \mathrm{I}$ will then expand the discussion to some real-life illustrations.

We ordinarily take it for granted that actors in a play enact fictional roles, not their real-life personae. But what exactly does this distinction mean? Consider A, an actor in a play, who rages against her "husband," played by B, exclaiming "I hate you!" Now suppose that in order to add conviction to her acting, A can bring herself to a high level of emotional involvement in the play, so that at the relevant point in the plot she is in fact provoked into intense rage. Clearly, her exclamation expresses this emotion. At the same time, it would be ludicrous to conclude that $A$ does in fact hate $B$ even momentarily. $A$ and $B$ are the best of friends, and their friendship is forged rather than suspended during their common performances. The puzzle, in other words, is this: A's utterance expresses an intention, but in an important sense the intention does not belong to the speaker.

One difficulty in resolving the puzzle arises from the fact that A's exclamation of hatred on the stage is accompanied by a surge of rage no different in intensity from what A might feel and express at home. The difference between the theatrical performance and its domestic counterpart is not simply phenomenological. Nor should we say that A is merely performing the role of a wife in the theater. The concept of role extends beyond the theater and reaches into the household. There too, to be a wife-or a husband-is to perform a role, and simply pointing out that one role is "fictional" while the other one is "real" only restates the puzzle without solving it: we want to know precisely what makes one role performance "real" and another "fictional."

Some easy answers should be dismissed right away. For example, it would be a mistake to emphasize the limited duration of the actors' enactment of their roles as husband and wife. In a

17 See Role Distance, in Erving Goffman, Encounters: two studies in the sociology of interaction 83-152 (Bobbs-Merrill, 1961). The concept of role distance is applied in Goffman's essay, The Underlife of a Public Institution: A Study of Ways of Making Out in a Mental Hospital, in Asylums: Essays on the Social Situation of Mental Patients and Other Inmates 171, 318-20 (Anchor, 1961). Although I borrow the basic notion of role distance from Goffman, I modify it for my present purposes and employ it in ways that depart from his own use.

18 Compare Elizabeth Burns, Theatricality: A Study of Convention in the Theatre and in Social Life (Longman, 1972), and sources cited therein. 
long-running play their engagement on stage can outlast in the aggregate some real marriages. Nor is the intermittent nature of the theatrical role of great significance. The real marriage is no different in this regard, and the fact that we think only of the latter as continuous -as persisting even when the parties are off enacting other marriages on stage-is part of the puzzle rather than the solution.

Next, I want to discard summarily any suggestion that the crucial difference between the two kinds of marriage lies in the fact that the theatrical role is scripted and directed by others, whereas the domestic one is not. We can imagine in response an improvised play in which the actors enjoy no less textual and behavioral freedom than that allowed a couple who live, let us say, under the constantly vigilant scrutiny of parents and inlaws. Finally, it cannot be said that the real spousal role differs from the theatrical in the former's greater importance to its occupant. The opposite may well be the case. An actor may value his on-stage role as Desdemona's husband, and Desdemona her role as Othello's wife, much more than they value their relationships with their respective partners at home.

My suggested conception of the self offers a solution to the puzzle. The self, we said, is at least in part constituted by its social roles. But a self is not a mere concatenation of roles. To form a single self, a bunch of roles must be unified in some fashion. A self, we might say, is an integrated set of social roles. What does the integration consist in? The answer I suggest is metaphorical. The different roles must be "proximate": they must form a dovetailing, interrelated, and interacting arrangement that we can imagine as possessing a certain "density" or as forming a "core." Such a spatial depiction of the self makes immediate room for the possibility that a person-by which I mean a human individual as ordinarily understood-may occupy roles that are only tenuously connected to the elements forming that core; the ties may become too distended to still count such roles as integral parts of the self. The notion of role distance conveys this possibility. $^{19}$

18 Analogously, Harry Frankfurt drew attention to the distinction between "internal" and "external" mental states. He too used a spatial metaphor to demarcate a certain boundary line around the self and to separate out some elements that ordinarily would likely be ascribed to the same individual. See Identification and externality, and Identification and wholeheartedness, both in Harry G. Frankfurt, The importance of what we care about: Philosophical essays 58, 58-62; 159, 167-76 (Cambridge, 1988). 
The sketch I have drawn so far is static, but to meet our present needs I must add to it a dynamic component. Let me call the process by which a new role gets attached to the preexisting constituents of the self identification. A person identifies with a role when it is allowed to sprout enough connections with existing constituents of the self. An individual's proclivity to identify with any new role can be understood in terms of the dynamic properties of the person's existing roles-how prone they are to hook up or interact with the new addition. But although identification describes an inner or subjective process by which the self is shaped and modified, it is unlikely to be, in general, idiosyncratic. The propensity to interconnect or detach is itself a property of roles that is shaped by the same social practices and understandings that mold other aspects of the role. The precise way in which roles combine in individuals may vary, but we should expect to find at least rough uniformity regarding the relative proximity or distance of particular roles.

Although crude, this sketch of the self can clarify the contrast between marriages on stage and at home. This contrast is a matter of the different degrees of integration between the respective roles and their associated states of mind on the one hand and the subject's self on the other. Unlike the domestic role, the theatrical one is distant: it is relatively removed or disconnected from the actor's other roles. Consequently, the rage she experiences and conveys on stage is external: neither A nor others see it as continuous and intertwined with A's other mental states.

Evidence for these characterizations can be found in our respective approaches to construing the theatrical and the domestic episodes. In the former case, our explorations would be strictly confined to the theatrical role, implying a sharp separation between this segment of A's life and the rest of it. In trying to understand A's on-stage verbal assault, we would not deem relevant information about A's attitudes toward other people or even toward B. By contrast, this information would be highly relevant to our understanding of a domestic feud. We wculd naturally view the emotional outburst as continuous with A's other roles, such as mother or sister, and as related in potentially revealing ways to her attitudes toward other people, and to her aspirations, frustrations, and the like.

Returning from our foray to the theater we can now contrast, along similar lines, two real-life roles: parent and telephone operator. Attending first to our protagonists' speech behavior will provide an immediate link to our discussion of the play. Suppose 
that someone helps my four-year-old daughter to cross the street just as I happen to walk by. Being in general a polite fellow, I say to the benefactor, "Thank you for helping my daughter." Three characteristics of this scenario are particularly noteworthy. First, my expression of gratitude is strictly a matter of performing my role as father. After all, the benefactor has not rendered any help directly to me. Only by virtue of the parental role does my thanking the helper become both appropriate and necessary. Second, no special question about my motivation to comply with the role's requirement arises in this case. When enacting a parental role, I behave in my "personal" capacity, exhibiting such characteristics as a general disposition to be a polite person. Finally, since I fully identify with my parental role, my expression of gratitude is sincere-it would be generally expected to convey truthfully my genuine sense of gratitude. ${ }^{20}$

Contrast this episode with another familiar display of politeness. Our second protagonist is an AT\&T operator. As anyone who has ever needed his or her assistance knows, the operator concludes each exchange by proclaiming: "Thank you for using AT\&T." Now on the face of it, this utterance is on all fours with the "thank you for helping my daughter" I address to her benefactor. Still, the differences are striking. Consider motivation first. Unlike the grateful father, the operator's recitation of thanks bears no relation to a personal disposition to politeness. This feature of the situation both follows from and testifies to the fact that the politeness evinced by the operator remains external to him. Both roles-the parent's and the operator's-contain the quoted utterances in their respective scripts. But, unlike the parent's role, the operator's role remains at a distance. The fact that the role of operator mandates an expression of gratitude on certain specified occasions has in itself no hold over the role player. There must be some other source of motivation to compel his utterance of the required text. Such motivation may be either inducement or coercion. A recalcitrant operator surely will be threatened with dismissal if he fails to perform the incantation, irrespective of the earnestness of his belief that the required practice is silly and inappropriate. Or imagine the operators going on strike, their union decreeing: "No more of this 'thank you' silliness until we get a raise." It would seem altogether appropriate for AT\&T to meet the union's demands by actually

${ }^{20}$ On sincerity as a condition for the performance of a speech act, see John R. Searle, Speech Acts: An Essay in the Philosophy of Language 60-67 (Cambridge, 1969). 
paying the operators to perform that particular aspect of their task.

Finally, observe that the norm of sincerity does not belong in this language game. Professor John Searle, a leading speech-act theorist, supports the claim that the requirement of sincerity is a condition for the successful performance of a speech act by observing that "it is linguistically unacceptable (though not selfcontradictory) to conjoin the explicitly performative verb with the denial of the expressed psychological state. ${ }^{21}$ One cannot say, "thank you, but I'm not really grateful." However, in the operator's case we can find an opposite and equally instructive oddity. It would be quite ludicrous for the overly zealous telephone operator to say, "Thank you for using AT\&T," and then add: "And I really mean it." The oddity would not disappear even if the particular operator happened, in fact, to experience a sense of gratitude, born of a belief that his own livelihood is secured by the customer's patronage. The conclusion that the norm of sincerity does not apply in this context is both a product, and evidence, of role distance-that is, of the detachment between the operator's role-oriented actions and intentions and other aspects of his self.

\section{The Formal Synthesis: Constructing Collectivities}

\section{A. The Conceptual Framework}

I turn now to the formal synthesis of roles-their combination to form collective entities. The first thing to observe is that not all roles participate in forming any collectivity at all; they are, on the formal side, free-floating atoms in social space. The roles of painter and free-lance writer belong in this category. Let us call such roles personal, in contrast to collective roles, the latter being roles that do form part of one collective entity or another. ${ }^{22}$ In what follows I ignore personal roles and focus exclusively on collective roles.

${ }^{21}$ John R. Searle, Expression and Meaning: Studies in the Theory of Speech Acts 4-5 (Cambridge, 1979).

${ }_{22}$ We should not expect a sharp line between personal and collective roles. The distinction depends on our practices of unifying and labelling a set of roles as one or another collective entity, and these practices are not altogether settled. To be sure, the role of a free-lance writer, for example, is also systematically related to other roles-to different publishers, for instance-but the relationship with any particular role is too transient in this case to invite or uphold unification into a single, enduring collective entity. But there is plenty of room here for borderline cases and disagreement. 
Collective roles divide into collectivity-specific and collectivitygeneral roles. Being part of a particular collectivity is an essential part of the former role, whereas the latter can be enacted within any collective entity that belongs to the same general type. An example will help clarify the point. Consider again the role of parent. One is not a parent first, and the parent of someone in particular (within a specific family setting) second. Being a parent is always and essentially being the parent of some particular child. Being a law professor, in contrast, is not so tied to a particular collectivity. The role is defined apart from a connection to any particular law school. Although one must be a law professor at a law school, any school would in principle do.

Among the collectivity-specific roles one kind has special significance. This is the self-referentially defined role of "being a member of collectivity X." So whereas the role of "law professor" is collectivity-general, being a "Boalt Hall law professor" is collectivity-specific. Clearly each collectivity comprises such selfreferentially defined roles. I will call such roles affiliation roles, and all other collective roles primary roles. In this terminology law professor is a primary role, whereas Boalt Hall law professor is an affiliation role.

We can now combine the description of the material synthesis of roles with their formal synthesis. Note first that each of the types of roles I have distinguished-primary and affiliation - can be enacted in a distant or a proximate manner. Secondly, a primary role and the related affiliation role can be enacted at different distances. For example, I can identify with my role as law professor, while keeping my affiliation role as a Boalt Hall law professor at a distance. This is particularly likely to be the case when, as in this example, the primary role is proximate and collectivity-general. The role of professor can be performed without great disruption while its holder moves between different universities. Consequently, one's attachment to any particular collectivity of this kind will be perceived and experienced as contingent and tentative, and hence one's affiliation role in it will be a relatively distant one. The opposite is the case when a proximate primary role is collectivity-specific, as in my parent example. Since being a parent essentially involves affiliation with a particular family, my role as "father in the D-C family" is as proximate as my parental role itself.

\section{B. The Continuum of Collectivities}

Based on these considerations, we can distinguish four types 
of collectivity as shown in the following table:

Types of Collectivity

\begin{tabular}{cc|c|c|c|c|} 
& & $\begin{array}{c}\text { Integrated } \\
\text { community }\end{array}$ & Institution & $\begin{array}{c}\text { Shell } \\
\text { community }\end{array}$ & Organization \\
\cline { 1 - 4 } & $\begin{array}{c}\text { Primary } \\
\text { roles }\end{array}$ & proximate & proximate & distant & distant \\
\hline \multirow{8}{*}{$\begin{array}{c}\text { Affiliation } \\
\text { roles }\end{array}$} & proximate & distant & proximate & distant \\
\hline
\end{tabular}

Let us consider each in turn. ${ }^{23}$ The first type of collectivity-I call it an integrated community-consists of proximate primary and affiliation roles. In light of what we have just said about the parental role, a suitably idealized version of the nuclear family provides the paradigm example. ${ }^{24}$ At the other extreme we find a type of collectivity I call organization. Recall the telephone operator who served earlier as an example of a distant primary role. We can now add the observation that it is of little consequence, so far as the operator is concerned, whether he performs that role as part of AT\&T or Pacific Bell. The AT\&T operator's affiliation role is as distant as his primary role. AT\&T

${ }^{23}$ These categories are to be understood as "ideal types" (in the Weberian sense), designed to assist us in recognizing and analyzing real-life phenomena. A number of important idealizations involved in constructing the four categories should be mentioned. First, role distance is best seen as a continuous variable, but for the sake of simplicity I reduce it to a binary one by juxtaposing "proximate" and "distant" roles. Second, each collectivity is likely to comprise roles of varying distances; we can attach the labels I propose to actual collective entities only by identifying a dominant pattern of role distance in them. Third, even a single individual's distance to a particular role may fluctuate. To ascribe to an individual a fixed distance from a given role accordingly requires that we ignore such fluctuations or average them out. In light of these idealizations, the most accurate use of the proposed typology would be to classify discrete relationships of individuals to their collectivities. For example, we could say that a particular member has at a given time an organizational relationship to a specific collectivity, whereas that same member at a different time, or a different member, may have a communal relationship to the same collectivity. But though this application of the typology would be the most accurate, it would not be the most useful. It would often be fruitful, despite the inaccuracy, to generalize over both time and individuals by fitting a given collective entity into one pigeonhole or another.

24 Another clear example is that of a priest, for whom the primary role is proximate and collectivity-specific, and hence the affiliation with the particular church is a proximate one too. 
can thus be seen as the union of distant primary and affiliation roles, and hence as an organization.

Between the two polar collectivities we find two intermediate categories marked by disparity in the distance of the primary and the affiliation roles. Being a professor, I suggested, is a proximate role that its holder can perform with considerable continuity while moving from one university to another. The university thus unifies proximate primary roles and distant affiliation roles. I call such collectivities institutions. The last type of collectivity-I call it a shell community - consists of proximate affiliation roles and distant primary roles. ${ }^{25}$ Think, for example, of a religious cult-call it $\mathrm{C}$-whose devout members engage in a variety of jobs with the purpose of financing the cult's collective spiritual activities. These jobs may define for the members distant roles; the one thing that matters about these occupations is that they are performed for or on behalf of C. Accordingly, the affiliation role of being a member of $\mathrm{C}$ is a proximate one. A more problematic but also more common example of a shell community is provided by many geographically defined collectivities-a village, a state, even a nation-with which people identify more deeply than with the primary roles they perform within them. A good though crude test by which to distinguish a shell community from an institution is whether the members would prefer to change their primary roles, such as their occupation, to remain in the collectivity, or would they rather shift collective affiliation to preserve or promote their primary roles. ${ }^{26}$

\section{LAW AS SCRIPT}

How does law fit into this picture of selves and collectivities? In order to devise a role-atomistic conception of law, I start from the common view of law as a system of norms that guide the behavior of individuals and collectivities. Add to this our earlier observation that the idea of role contains the notion of a script consisting in role-defining norms. The result is a picture of law as

25 The reader should be alerted to unintended connotations that this label may have. Specifically, there is nothing "empty" about what I designate as a shell community; rather such a community consists of genuine and important bonds among its members. The image of a shell is only meant to convey the disparity between the significance of one's very membership in such a collectivity and what one actually does while being a member.

26 The individual's preferences only provide a rough test because people need not always value elements of their identity over other considerations. Moreover, a person may even want to change a role precisely because of its proximity, as a way of bringing about a fundamental change in one's self. 
guiding behavior by participating in the scripts of social roles. Lawmaking, accordingly, is for the most part a form of social scriptwriting. On this view law addresses, at bottom, neither individuals nor collectivities. Instead law operates at the level of social roles-the building blocks from which both individuals and collectivities are constructed. By rewriting the scripts of existing social roles and by scripting new ones, the law shapes with a single stroke individuals and collectivities alike.

\section{A. Ways of Scriptwriting}

Law participates in scripting social roles in many ways, but a few are particularly significant. Consider first the way law helps set the entry and exit conditions of various roles. This is an extremely broad category, ranging over such disparate areas as marriage and divorce, hiring and dismissal, immigration, elections, and many more. In all of these areas, the law sets out conditions for assuming and shedding a certain role-of a spouse, an employee, a citizen, or a legislator. The significance of these conditions, and hence of the laws that define them, goes beyond determining who will hold a given role and for how long. The ease or difficulty with which a role can be acquired or vacated bears importantly on role distance. Other things being equal, the more enduring and secure a role, the more likely it is to be perceived and enacted in a proximate rather than a distant fashion. Thus, the boundary conditions the law sets on a role are determinants in the construction of selves, in whom these conditions influence the relative location of a given role in the self's topography. The same boundary conditions also serve as gatekeeping devices in the corresponding collectivities. This too goes beyond helping determine the membership of the different collectivities. By influencing role distance, legal boundary conditions help fix or change the nature of a collective entity and its location on the organization-community spectrum.

A second way in which the law shapes roles is by formulating or reinforcing some of the norms that govern them: Parents are required by law to provide for their children, and public officials are forbidden from accepting bribes. Here too, impact on the role has repercussions on the corresponding collectivity: families are understood, in part, as collective entities designed to provide for children's needs, and public institutions are defined in part by an ethos of impartiality and fairness. In these examples, the law addresses directly specific roles-those of parent or official. The law can also, however, address a collective entity as such-by 
imposing liability on a corporation, for example, or by enjoining certain hiring practices by a university. However, to be effective, such legal imperatives must also modify particular roles by indirectly changing their scripts.

Law can shape roles piecemeal, but it can also operate in a wholesale manner by formulating general provisions that apply across the board, without special reference to any particular role. Such, for example, are most of the provisions of a criminal code: they forbid killing or arson by everyone, regardless of role. Our framework can accommodate such general provisions in two different ways. One is to view them as parts of a single script defining a distinct, though broad and pervasive, role such as "citizen" or "resident" (or, in different terms, "American" or "Californian"). Alternatively, these provisions can be seen as grafted upon all (or most) other roles in society, adding a certain standard feature to their otherwise disparate scripts.

In addition to modifying existing roles, law also produces original scripts, creating entire roles that would not be available otherwise. The most obvious examples are roles that form part of the legal system itself, such as judge or juror. To play such roles one needs instruction in the relevant legal scripts. Other legally created roles are less formally structured. Think of the litigant, witness, or prisoner.

Lawmakers are not the only social scriptwriters. Many nonlegal roles are also charged with the task of writing or modifying other roles. This is true generally in hierarchical contexts, such as when the management of a business firm shapes the roles of its employees. The law, however, is often in a position to script-entirely or partially-these scriptwriting roles, thereby affecting indirectly the roles that are being shaped by the extralegal scriptwriters. This legal "superscripting" is a particularly important method of participating in social construction, because it allows the law to have widely ranging effects combined with a relatively low level of intrusiveness into the lives of the individuals and collectivities involved. Since the scripting activity by nonlegal role holders can take the same forms as the different kinds of legal scriptwriting I have listed-setting entry and exit conditions, regulating behavior, etc.-superscripting will also fall into the same categories. For example, the law can set some requirements-substantive or procedural-on employers' structuring of retirement plans, or on the disciplinary proceedings of schools or universities. 


\section{B. Scripting and Role Distance}

Law can intervene in principle in the formation of all social roles-it has in this regard a universal domain. Still, some roles are more amenable to legal intervention than others. Once again, I will focus on a single variable-role distance-and ask what difference it makes to a role's amenability to legal change. The answer will take the form of a number of speculative hypotheses. Each of these hypotheses must be read with an emphatic ceteris paribus clause attached.

First, the more distant a role, the more amenable it is to legal change; conversely, proximity will make a role more change resistant. The main reason for this conjecture lies in the density of ties between a proximate role and other parts of the self. A proximate role is in this way more deeply entrenched, and therefore less malleable. The opposite is true of a distant role.

Second, success in changing a proximate role is likely to be more enduring than success in changing a distant role. This hypothesis is simply the converse of the first one; the change in the proximate role will be more entrenched and hence more changeresistant than a change in a distant one.

Third, changing a proximate role will be more effective than changing a distant one. As we saw earlier, a distant role requires policing and external inducements to secure compliance with its norms. The norms of a proximate role, by contrast, are internalized, thus guiding behavior from the inside, as it were. Consequently, a legal change in a proximate role's script will be more self-executing, providing a relatively reliable source of guidance for the individual's subsequent behavior.

Finally, a change in a proximate role is more intrusive and has more unpredictable consequences than a change in a distant role. This difference results from the wider repercussions throughout the self in the former case, as against the more contained and isolated effects of the change in the latter situation.

Taken together, these hypotheses suggest that the stakes in a legal change of a proximate role are higher-on both the positive and negative sides-than those of changing a distant role. Changing a proximate role presents a greater risk of failure or harm, but it also promises more enduring, effective, and pervasive results in case of success.

Corresponding hypotheses can be formulated on the collective level. To do so, we must take into account the presence in each collectivity of two types of roles-primary and affiliation-and pay attention to which of these the law attempts to 
change. Here again it is simplest to generalize about the two polar entities-organizations and integrated communities. Since in an organization, such as a business corporation, both the primary and the affiliation roles are distant, an attempted change should be relatively easy and harmless, but implementing it will require ongoing monitoring and enforcement. The converse holds with regard to integrated communities such as families and churches. Reshaping them is a riskier proposition, both in terms of likelihood of failure and potential for harmful results; but success, if attained, will be more enduring and self-sustaining.

The intermediate collectivities present a mixed picture. In the case of institutions-the university was our example-changing an aspect of the distant affiliation role would be both easier and less risky than trying to reshape the more proximately held primary roles. In contrast, exerting influence over a shell community, such as might exist in a village, by changing its proximate affiliation roles would be harder and riskier than trying to influence it by tampering with its distant primary roles. But again, the payoff in terms of the durability and effectiveness of the change will be different too.

I have so far treated role distance itself as inert to the law's intervention. However, role distance too can be affected by law, either deliberately or as a side effect. The following hypothesis concerns this possibility. Other things being equal, any legal interference with a role's script is likely to increase that role's distance. Recall our earlier observation that the scripts of proximate roles provide the individual with internal sources of motivation and guidance, whereas distant roles require the support of some externally supplied inducement or enforcement. But this characteristic describes a two-way relation: the mere presence of external measures to secure compliance with the role's norms may engender alienation and distance. Given the correlation between external inducements and distance we are likely to associate the presence of such inducements with role distance and their absence with proximity. Consequently, the external inducement may simply act as a signal of distance. Moreover, external efforts to secure compliance with a role, especially when they assume a coercive form, may breed resentment, resistance, and defiance. A likely result is a tendency to disassociate oneself from the source of such intrusive intervention by severing the ties between the culprit role and other aspects of one's self. Finally, even beyond such a defiant impulse, the mere existence of systematic coercive efforts to enforce role performance may dull or overwhelm the 
corresponding inner motivations exerted by the proximate role itself. The natural flow of one's role behavior is disrupted and the integration of that role with other parts of the self shattered when one is constantly mindful of one's role performance being monitored, with every lapse subject to sanction. When the law tampers with a script, it typically adds the threat of sanctions to enforce the change. For the reasons just listed, by doing so the law is likely to convert a proximate role into a more distant one. ${ }^{27}$

Should we welcome or decry this likely effect of legal intervention? We have so far delayed an evaluative consideration of the variations in the constitution of selves and collectivities that we canvassed. We must turn to such an evaluation now.

\section{LAW AND THE STRUCTURE OF THE SELF}

By writing or revising the scripts of social roles, the law participates in the constitution of selves and in the construction of collectivities. But what guides the law in this endeavor? What is the purpose or the point of the scripts it composes? To answer this question, virtually all the policies, values, and other normative considerations that are ordinarily thought to guide the law would have to be transcribed into our role-centered model. But not all such transcription would be fruitful. Rather, the role perspective is especially well suited to highlight a particular range of concerns regarding individual identity and its relationship to different forms of collective life. I will organize my comments on this topic under four headings: "the optimal topography of the self," "managing distance," "preventing harm to self," and "collective transformations."

\section{A. The Optimal Topography of the Self}

To assess the comparative value of role-proximity and roledistance, let us consider two polar possibilities: a self characterized only by proximate roles-a proximate self, for short-whose collective life is bound up exclusively with integrated communities; and a self whose roles are all distant-call it a distant self-whose collective involvement is always organizational in

27 But bear in mind the ceteris paribus proviso. For example, legal intervention may counter other forces that increase role distance, so that the law's contribution may in the end result in a net reduction in distance. 
nature. Both these extremes represent, I believe, pathologies of personhood.

The best way I can express the intuitive desirability of proximate roles is by drawing attention to a familiar range of impressions and judgments. We often experience ourselves and others as more or less substantial, as having or lacking a firm and wellformed identity. We describe people as heavyweights or lightweights, as deep or shallow, as simple or complex. The seat of these metaphoric qualities is the "core" of the self. By forming the self's core, proximate roles give us substance and solidity; these would be the proximate self's dominant characteristics. One important problem, however, that such a self would face is change. As long as it enjoys complete stability, such a self can perhaps flourish. But its fixity and rigidity make it brittle: an alteration or loss of any one role will send shock waves throughout the entire self threatening to shatter its identity.

Distant roles, by contrast, are sources of versatility and resilience. One can assume or discard a distant role without significant repercussions in other parts of the self. Consequently, a distant self weathers change very well. The reason that modifying or replacing any one of its roles will not shatter its identity, however, is that there is no clear identity to shatter. The distant self's pliability is purchased at the price of lacking a firm and cohesive core; such a self is a void going through the motions of performing one role or another without a substantial and coherent identity.

These considerations suggest an optimal topography of the self containing a gradation of distances. This conclusion underscores the benefit to the self of membership in integrated communities as well as organizations. A similar mix of distance and proximity can also be attained by affiliating with intermediate collective entities-shell communities and institutions.

An optimal mixture of roles would also take into account the distinction between primary and affiliation roles. Proximity and distance take on somewhat different shades of significance in regard to the two types of role. Proximity in affiliation roles is specifically related to stability and durability in one's interpersonal relationships, while distance in these roles is consistent with greater variability and lesser vulnerability to loss or change in interpersonal relationships. Primary roles give rise to different concerns. Here the emphasis is on continuity or change in performances relating to such things as one's occupation, irrespective of 
the particular interpersonal setting within which they are engaged.

What are the normative ramifications of these reflections? First, all four kinds of collectivity that we have distinguished have their distinct merits, so that a proper balance of roles and distances requires that they all be cultivated and protected. This conclusion has special significance in light of the recent ascent of a communitarian ideology, which in effect endorses a single form of collective affiliation and presents it as an exclusive ideal. ${ }^{28}$ This is not to denigrate the importance of promoting community in a world in which distance-engendering organizations predominate, while many traditional forms of communal proximity have disintegrated. But endorsing community must be qualified not just by recognizing the self's need for distance as well as proximity, but also by another salient feature of modern life-a high level of change. It may be both desirable and possible to contain the rate of change in certain areas. Still, flux is likely to remain dominant, suggesting a second caveat to the communitarian agenda. Where the level of change remains high, forging communal ties-as well as encouraging other forms of role proximity-may become a trap to selves whose resilience will be weakened in the face of inevitable changes, increasing their vulnerability to identity-shattering experiences. Using the last consideration as a clue to the relative suitability of different types of collectivity, we can now move beyond the blank endorsement of all four collectivity types. The task is to accommodate change by correlating different social structures with the varying tendencies toward stability or change in different spheres of social life.

\section{B. The Management of Distance}

The first set of social practices that affect role distance I call compartmentalization and spillover. By compartmentalization I mean practices that treat a particular role as separate from other aspects of the self. Spillover describes the opposite attitude of

${ }^{28}$ For some communitarian writings on this theme, see, for example, Sandel, Liberalism and the Limits of Justice (cited in note 11); Allan C. Hutchinson and Leslie J.M. Green, eds, Law and the community: the end of individualism? (Carswell, 1989). In his recent semiofficial manifesto of the communitarian movement, Amitai Etzioni underscores the significance of various other institutions, but their value is seen as deriving from their contribution to community. See The Spirit of Community: Rights, Responsibilities, and the Communitarian Agenda 134-60 (Crown, 1993). 
indiscriminately attending to or affecting a number of different roles, disregarding the boundary between them.

Take for example the workplace. Consider first the seemingly trivial, but symbolically significant, matter of clothing. Here we encounter the official uniform, a highly compartmentalizing requirement, at one end of the spectrum; a more or less formal dress code would fall in the middle of the spectrum; and casual dress, continuous with the employee's after-hours attire, would be an example of spillover. Less visible, but probably more important, is the issue of managing information: how strictly role-related should be the information a person is encouraged or required to reveal in carrying out different roles? ${ }^{29}$ Finally, which aspects of an employee's life may the employer seek to influence or regulate? Here again there is a wide range of possibilities, and they include aspects of the employee's speech, behavior, and life-style, both during work and outside of it. ${ }^{30}$

Although all such practices influence role distance, their precise effects are uncertain. Generally, compartmentalization accentuates the boundary of a role, thereby inducing distance, whereas spillover fosters proximity by effacing a role's boundary and encouraging a more unified and integrated vision of the self. These practices, however, may also backfire and have opposite effects on the structure of the self. For example, when spillover is perceived as an unwelcome intrusion into zones of the self outside the employer's legitimate concern, it may induce greater role distance; the employee, driven by resentment, may erect a higher inner barrier between her self and her occupational role, even as she goes through the motions of complying with the demands made by the employer on other parts of her self.

The second set of distance-affecting practices I consider concern ascribing responsibility. ${ }^{31}$ Although people are primarily

29 Consider in this regard the changing attitudes and policies toward the exposure of officials' private lives and the legal protection that the "public figure" doctrine provides for such exposures against possible libel suits. See New York Times Co. v Sullivan, 376 US 254 (1964). Such a legal doctrine and the practices and attitudes it promotes can be seen as a vote against role distance with regard to officials brought about by creating informational spillover between this role and other aspects of the official's life.

${ }_{30}$ These questions have been widely litigated. See, for example, Novosel $v$ Nationwide Insurance Co., 721 F2d 894 (3d Cir 1983) (asking whether a private-sector employee may be fired for saying disparaging things outside work about a legislative initiative his employer is promoting); Minnesota $v$ Porter Farms, Inc., 382 NW2d 543 (Minn App 1986) (asking if a private-sector employee may be fired for not marrying the woman with whom he is living).

${ }^{31}$ I deal with these issues in greater detail in Meir Dan-Cohen, Responsibility and the Boundaries of the Self, 105 Harv L Rev 959 (1992). 
held responsible for their voluntary actions, roles often expand or contract such responsibility. Consider expansion first. Under such headings as vicarious and collective responsibility, the occupants of certain roles are held responsible for the actions of others. For example, parents are often held responsible for their children's actions. Similarly, whether or not recognized by law, instances of collective responsibility abound. From the relatively simple case of the baseball player who reports in the first person plural about an inning or a victory ("we scored," "we won") in a game in which she did not even participate, to the more complicated situation of the American for whom space missions or the Vietnam War are matters of personal pride or shame, we witness all around us collective affiliation leading people to treat the actions of others as their own. These attitudes and practices reflect as well as forge the proximity of one's affiliation role. Such solidarity expresses and reinforces one's identification with the collective role and through it with the collectivity of which that role forms a part.

In the opposite situation, acting within a given role can reduce or eliminate responsibility for one's own actions. Think for example of the "Privileges and Immunities" that exempt government officials from personal responsibility as long as they act within the confines of their official role. ${ }^{32}$ Whatever the historical or pragmatic reasons for this immunity, its effect is to forge or reinforce role distance. We commonly think of the role of official as impersonal; withholding personal responsibility for actions performed in one's capacity as an official is one of the practices that help to erect the barriers that separate this role from the rest of the self.

Role-based exemptions from responsibility are not limited to government officials. The corporate world-conventionally classified as part of the "private sector"-also contains many arrangements intended to shield its actors from personal responsibility for the consequences of their role-related behavior. Indeed, perhaps the most radical constitution of role distance secured by a formal restriction on responsibility occurs in the corporate area: the limited liability of shareholders. Shareholding thus becomes a paradigm case of a distant and highly confined form of collective affiliation.

${ }^{32}$ See, for example, Laurence H. Tribe, American Constitutional Law 268-74 (Foundation Press, 2d ed 1988). 


\section{Preventing Harm to Self}

Another normative implication of the role-perspective concerns a special kind of harm, and corresponding new protections, that the approach brings into sharp relief. It is the harm to self and identity that can result from changes in one's social roles.

I have mentioned earlier the law's participation in setting entry and exit conditions for different roles and collectivities. We can now glimpse some of the normative underpinnings of this activity. They stem from two related observations. First, that greater damage to self results from losing a proximate role than from losing a distant one. Second, that distant roles are more fungible in terms of the actor's identity than proximate ones; each proximate role's dense ties with other parts of the self make it unique, and hence not easily replaceable. Together these two observations imply a ranking of role-exit in terms of relative damage to the self. Losing a distant role when a substitute is readily available is least injurious to self; but even without replacement such a loss will be less significant than the loss of a proximate role. In the latter case too, the availability of a substitute role may over time mitigate the harm, but for the reason just stated the possibility of a successful replacement is much more remote.

Applying these schematic conclusions to the four types of collectivity we have distinguished generates the following principles. An organization's reassigning its members to different tasks raises the fewest concerns for identity and self. Terminating membership in an organization is not of much greater concern so long as another organizational affiliation is available. Similar to the organization, the shell community can also freely reassign members to different primary roles without deep repercussions to self. Unlike the organization, however, a shell community expelling a member exacts high costs to that individual's self and identity. The case of the institution is again different. Institutions are internally more rigid than both organizations and shell communities: given the proximity of the primary roles, these roles cannot be easily changed or reshuffled. On the other hand, institutional affiliation is by itself of lesser moment. The harm to self of terminating institutional membership depends crucially on the availability of alternative institutions within which the expelled members can continue to engage in the same primary role. Finally, in the integrated community both primary role and affiliation are proximate, and removing a member from one role or the other is therefore highly detrimental to self. 


\section{Collective Transformations}

I have so far focused exclusively on the significance of variations in role distance to the individual, but collectivities also have a stake in these variations. We should thus expect collective entities to initiate changes in the distance of their members' roles. By taking account of the normative considerations that may guide collectivities in these endeavors, we can now add to our typology of collective entities a dynamic component. The location of a collectivity on the continuum that I have described earlier need not be fixed once and for all. Changes in the members' role distance entail movement of the collectivity along that continuum. We can think of such movement as propelled by the gravitational force of the two polar entities, exerting an attraction in the direction of organization on the one hand and toward community on the other.

Consider first the communal pull on an organization. Decreasing the distance of its members' affiliation roles has two kinds of advantages for the organization. As we saw earlier, so long as both the primary and the affiliation roles are distant, it takes special devices-such as payment and coercion-to motivate compliance with a role's demands. By converting the member's affiliation into a communal one, the organization can hope to tap a new source of motivation that will improve performance while reducing the costs of inducing and policing it. The second advantage is greater stability. By increasing the members' collective ties it becomes easier-that is to say also cheaper-to retain them in the organization and prevent departures. Think, for example, of a corporation attempting to create for its employees a more communal environment by thickening and multiplying their corporate ties. The corporation might try to cultivate loyalty, pride, and an esprit de corps by, for example, encouraging informal and multifaceted relationships among the employees and sponsoring activities and events outside their jobs. If these efforts are successful, the corporation may evolve from an organization to a shell community.

The communal efforts may, of course, fail. For one thing, given the obvious advantages to the corporation that I have mentioned, the employees may dismiss all such steps toward community as strategic and exploitative. In addition, moving toward community may involve a considerable gamble for the corporation. In attempting to realize its communal aspirations, the corporation may need to dismantle certain coercive and bureaucratic 
structures that will be hard to reinstate if the communal effort fails.

Indeed, even success in transforming an organization into a shell community has its price. For example, it must bring with it a heightened responsibility toward the individual employee. With thicker ties to the corporation come dramatically increased stakes for an employee to continue her affiliation with the corporation. This change must bear on policies regarding termination and layoffs. To discharge an individual from what has become a communal setting is to inflict a blow on her self and to shatter her identity. Such a step can be taken only under the most severe restrictions, if at all. ${ }^{33}$

Similar to the organization's shift toward a shell community is the institution's movement in the direction of an integrated community-similar, but not identical. Unlike the organization, in the institution the members' primary roles are proximate, so there is no need to spur adherence to them by fostering greater identification with the institution itself. The main institutional advantage secured by closer affiliation is a greater ability to retain members in the face of alternative opportunities. But just as the gains of community are slimmer here than in the case of the organization, the risks are smaller too. The proximity of the members' primary roles raises lesser anxieties concerning their job performance; consequently, not much is risked in loosening the coercive institutional grip over members entailed by the communal transformation.

The organization pole exerts an attraction that induces changes in the opposite direction. Consider shell communities first. Their instability results from the tension between the proximity of the affiliation role and the distant primary roles. What one actually does as a member of such a community is for the most part characterized by distance, and one's identification with one's community may simply fail to supply sufficient impetus for an adequate performance of the primary roles. The result may be increasing resort by the community to external pressures and inducements to compel the members' role behavior. Such measures, however, are likely to alienate the members from the community itself, rendering their affiliation with it increasingly distant. The result is a greater resemblance between the shell community and an organization.

${ }^{33}$ See Section VI.C. 
An institution, too, can move in the organizational direction, driven by increased distance of the members' primary roles. Let me mention two possible reasons for such a change. First, there may be a shift in the social understanding or meaning of a particular role. Such a shift may, for example, erode the vocational aspect of the professor's role to the point where it is done by rote without much personal involvement. Second, an institution may become intrusive and assertive in shaping its members' primary roles. Although these roles are, ex-hypothesi, collectivity-general, so that the members could in principle leave the oppressive institution for some other institution, certain conditions-such as unemployment in the relevant area-can de facto force the members to stay where they are. The result may be an increasing alienation-induced by the institution's oppressive policies-of the members from their primary roles, to the point where the institution becomes an organization.

An integrated community enjoys greater internal stability than either the institution or the shell community. Since in the integrated community both the primary and the affiliation roles are proximate, it is less likely that one of them will trigger the distancing of the other that might occur in the two other kinds of collectivity. Integrated communities are, however, obviously as vulnerable as any other entity to an external redefinition of their roles. So, for example, we can imagine a change in the public perception of the parental role-our paradigm example of a proximate communal role-such that the role becomes more distant, moving the family in the direction of a shell community. The attempt to collectivize child rearing in the early days of the Israeli kibbutz is possibly an example. We can also see how a dramatic surge in surrogate parenthood, foster-home arrangements, and adoptions might have a similar effect on moving the family toward the shell community model.

Changes in the integrated community can be also triggered by a revised attitude toward the affiliation role. For example, we can imagine, and to some degree observe, a decline in the ideal of the family concomitant with a continued affirmation of deep personal involvements with the discrete roles, such as those of parent or spouse, that have been traditionally associated with the family. People may still enact these roles in a proximate fashion but within a collectivity-call it a commune-that is institutional in nature. Unlike the family, such a commune does not provide the members with a proximate affiliation role: membership in a particular commune does not have the same significance to the 
members' identity as affiliation with a family has. Instead the commune only loosely coordinates the members' primary roles.

Needless to say, the movement of an integrated community toward either the institutional or the shell-community model need not stop there. I have already discussed the processes that drive these types of collectivity in the organizational direction, and these processes would naturally apply to the transformed integrated community as well, moving it further along the continuum to the organizational pole. It should also be clear that this dynamic picture of collectivities does not assume any final resting place. As my earlier description of the communal pull suggests, the transformation of an entity into an organizational form can always be reversed, driven by the forces that constitute the attraction of the communal pole.

Through scripting and superscripting, the law can delay or accelerate such collective transformations. In doing so, however, it faces a dilemma-perhaps the dilemma-that the present framework helps reveal. The law, as other social practices, stands to its subjects in both a reactive and a constitutive relationship. The reactive relationship takes the subject and the present configuration of her roles as given, treating her in accordance with the existing inner boundaries and connections among those roles. The constitutive relationship realizes law's creative effect in reconstituting roles and their configurations in ways that will alter the subjects and their identities. When should the reactive aspect be emphasized and when should the constitutive effect take precedence?

\section{CONCLUSION}

I have concluded the preceding Section with an unresolved dilemma, but this obviously is not the only question left unanswered in this Article. Indeed the reader may feel that the approach I have sketched raised more questions than it answered. This, however, is not by itself an objection. The real test is, are the questions interesting? Do they seem worth pursuing? Unfortunately, these metaquestions must also be left dangling at this point, their uncertain answers timorously hiding behind the "toward" in my subtitle.

There is, however, one particularly nagging query that challenges a basic premise of my role-atomistic approach. Aren't individuals at their authentic best precisely when they transcend or defy their assigned social roles? I have my own doubts, as well as a vague sense of a number of directions in which answers 
consistent with the role-atomistic approach may be found. I will mention just one. Even transcending or defying roles is a stance taken in a systematic and patterned relationship to those roles, and is to that extent governed by them. Much as in the famous drawings by Escher, the spaces among the roles are also shaped, though negatively, by those roles, to form what we may think of as counter-roles. There is, in other words, a crucial and wellrecognized difference between being original or rebellious and being crazy.

But then, even this may be inaccurate. Madness too is perhaps a scripted social role, complete with its own collective structures, that can be enacted with proximity or distance. ${ }^{34}$ Recall King David, then not a king yet, running for his life from King Saul, seeking asylum in Gath. In order not to appear threatening to the servants of Achish, the king of Gath, the Old Testament tells us, David "changed his behaviour before them, and feigned himself mad in their hands, and scrabbled on the doors of the gate, and let his spittle fall down upon his beard. ${ }^{n 35}$ Quite an act.

34 Compare Michel Foucault, Madness and Civilization: A History of Insanity in the Age of Reason (Vintage, 1973) (Richard Howard, trans).

${ }^{25} 1$ Samuel 21:13. The performance was convincing: "Then said Achish to his servants, $\mathrm{L}_{0}$, ye see the man is mad ...." Id at 21:14. 
HeinOnline -- 61 U. Chi. L. Rev. 12441994 